\title{
APLICAÇÃO DO MFV E CARACTERIZAÇÃO DAS ATIVIDADES DE FLUXO DO PROCESSO DE EXECUÇÃO DE ALVENARIA CONVENCIONAL
}

\author{
MFV application and characterization of process flow \\ activities conventional masonry execution
}

Tatiana Gondim do Amaral', Fabiana Barbosa de Resende ${ }^{2}$, Carlos Augusto Bouhid de Camargo Filho ${ }^{3}$

Recebido em 13 de setembro de 2016; recebido para revisão em 27 de novembro de 2016; aceito em 15 de fevereiro de 2017; disponível on-line em 24 de julho de 2017.

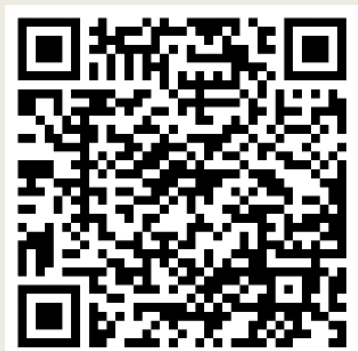

PALAVRAS CHAVE:

Mapeamento de fluxo de valor;

Construção Enxuta;

Transparência;

Alvenaria de vedação;

Perdas.

\section{KEYWORDS}

Value flow mapping; Lean construction;

Transparency;

Masonry;

Waste.

\section{* Contato com os autores:}

1e-mail: tatiana_amaral@hotmail.com (T. G. Amaral)

Enga. Civil, Doutora, Professora da Escola de Engenharia Civil e Ambiental da Universidade Federal de Goiás - UFG.

2e-mail: fabi1.eng@gmail.com (F. B Resende)

Mestranda do Programa de Pós Graduação em Estruturas, Geotecnia e Construção Civil - PPG - GECON.

${ }^{3}$ e-mail: carlos_bouhid@hotmail.com (C. A. B. Camargo Filho)

Mestrando do Programa de Pós Graduação em Estruturas, Geotecnia e Construção Civil - PPG - GECON. 


\section{INTRODUÇÃO}

A eliminação de desperdícios ou perdas é um dos principais objetivos da mentalidade enxuta por considerar que a presença desses absorve recursos sem que haja geração de valor (KOSKELA, 1992).

O conceito de perdas, por sua vez, já vem sendo relacionado à produção desde o começo do século XX. No entanto, foi a partir dos esforços de Taiichi Ohno em aumentar a eficiência de sua mão de obra, a fim de torná-la competitiva com a indústria automobilística ocidental e sua produção em massa, que o conceito atual, do ponto de vista da mentalidade enxuta, se difundiu (KOSKELA; SACKS e ROOKE, 2012).

No âmbito da construção enxuta, as perdas podem ser entendidas como a utilização em quantidades superiores as necessárias de materiais, equipamentos, mão de obra ou capital na produção da edificação (BØLVIKEN; ROOKE, KOSKELA, 2014; PÉREZ et al., 2015).

Em seus esforços para identificar as causas de desperdício na produção Ohno (1988) identificou sete tipos de perdas nos processos industriais, sendo elas por superprodução, por espera, no transporte, no processamento em si, por estoques, por movimento e pela produção de produtos defeituosos. No entanto, as particularidades da indústria da construção civil fazem com que essa classificação proposta não seja completa para o setor, sendo necessária a adaptação para esse contexto (KOSKELA; B ØLVIKEN, 2013).

$O$ entendimento das perdas, assim como dos tempos envolvidos nos fluxos de materiais e informações, é de suma importância para a melhoria dos processos, na busca pelo fluxo contínuo, otimização do fluxo de valor e, consequentemente, o estabelecimento de um modelo enxuto de produção. Uma das potenciais ferramentas utilizadas para a identificação desses problemas é o mapeamento de fluxo de valor (MFV) (WERKEMA, 2012).

O MFV é um diagrama simplificado de todas as etapas envolvidas nos fluxos de produção, necessárias para atender aos requisitos exigidos pelo cliente, desde o pedido até a entrega do produto final (MARCHWINSKI; SHOOK, 2003).

A aplicação do MFV já foi utilizada por diversos autores, como Bulhões e Picchi (2011) e Pasquelini e Zawislak (2005), sendo considerada pelos primeiros uma diretriz para o atingimento do fluxo contínuo e para os últimos, como um primeiro passo para a implantação da mentalidade enxuta em qualquer ambiente industrial.

Segundo Pasqualini e Zawislak (2005), a implantação do MFV é realizada em quatro etapas: a seleção da etapa construtiva, o mapeamento do estado atual, a análise do estado atual e a proposição de melhorias e desenvolvimento do MFV do estado futuro.

A racionalização, aumento da eficiência e o aumento da produtividade nos processos clássicos da construção civil, visando atender às necessidades dos clientes, é uma adequação cada vez mais exigida pelo mercado às empresas. Nesse contexto, à alvenaria de vedação, anteriormente caracterizada por baixa produtividade e regularidade geométrica, vem sendo incorporadas novas tecnologias de produção, com uma preocupação cada vez maior com os subsistemas que a cercam, como estrutura, sistemas prediais hidráulicos, sanitários e elétricos, etc. (BRANSTETTER; SANTOS; CARASEK, 2013).

Por outro lado, a escolha de novas tecnologias de produção deve ser realizada de forma criteriosa e sempre visando a otimização do processo produtivo. Desta forma, a utilização do MFV permite a identificação de gargalos e o surgimento de aplicação de oportunidades para essas novas tecnologias.

Diante do exposto reconhece-se a importância da alvenaria de vedação dentre os demais sistemas construtivos e com grandes possibilidades de perdas inerentes ao longo do seu ciclo produtivo.

Nesse sentido a aplicação do MFV poderia identificar essas perdas e garantir o atingimento do fluxo contínuo. 


\section{REVISÃO BIBLIOGRÁFICA}

\subsection{CARACTERIZAÇÃO DE ATIVIDADES DE FLUXO DO PROCESSO PRODUTIVO}

Através da elaboração do MFV é possível identificar as atividades de fluxo do processo produtivo, são elas: produtivas, auxiliares e improdutivas.

Para Santos, Formoso e Hinks (1996), as atividades consideradas produtivas são aquelas que agregam valor ao produto final. Já as atividades auxiliares são aquelas que, apesar de não agregarem valor diretamente ao produto final, são necessárias para execução do serviço. Estas, no entanto podem ser consideradas perdas se ocorrerem em quantidades superiores às necessárias.

Por fim, as atividades improdutivas são aquelas que não agregam valor ao produto, representando perda de tempo no processo. Essas perdas podem ser classificadas em evitáveis ocasionadas por falta de domínio no processo inevitáveis - ocasionadas por causas imprevisíveis ou ociosos - dada pela total inatividade dos operários (SANTOS; FORMOSO; HINKS, 1996).

\subsection{MÉTODOS PARA MENSURAÇÃO DOS FLUXOS E PERDAS}

São apresentadas a seguir métodos para mensuração dos fluxos e perdas:

(a) Ferramenta Diagrama de Processo (ISHIWATA, 1991): permite modelar o processo, tornando explícito o número e o tipo de atividades de processamento, inspeção, estoque e transporte, representando a sequência das diferentes atividades que compõem os processos estudados por meio do uso de símbolos. Sua utilidade é mensurar a percentagem das atividades de transporte em relação às atividades do processo;

(b) Ferramenta Mapofluxograma (ISHIWATA, 1991): permite modelar o processo e identificar o local de cada atividade, identificada por meio dos símbolos que representam as atividades e posicionadas em uma planta. Sua utilidade é identificar locais com maior ocorrência de perdas por transporte;

(c) Técnica da Amostragem do Trabalho (SANTOS;
FORMOSO; HINKS, 1996): permite determinar como o operário utiliza seu tempo e identifica os problemas e pontos a ser melhorados, sendo divididos em tempos produtivos, auxiliares e improdutivos. Por meio da técnica é possível mensurar a percentagem dos tempos produtivos, auxiliares (transporte inclusive) e improdutivos; e (d) Ferramenta Planilha com Registro Fotográfico (SOMMER, 2010): visa armazenar em um banco de dados às imagens referentes às perdas nas atividades de transporte.

\section{OBJETIVO}

O objetivo da pesquisa consiste em definir o MFV por meio da caracterização das atividades de fluxo e suas perdas no processo de execução de alvenaria de vedação com blocos de concreto sem função estrutural de uma empresa construtora goiana, com a finalidade de propor melhorias, a fim de reduzir a parcela de atividades improdutivas, otimizar as atividades auxiliares e aumentar a parcela das atividades produtivas.

\section{METODOLOGIA}

A pesquisa é classificada como estudo de caso, com abordagens qualitativas e quantitativas.

\subsection{CARACTERIZAÇÃO DA EMPRESA CONSTRUTORA E EMPREENDIMENOT OBJETO DE ESTUDO}

A empresa atua no mercado goiano desde 1986. Foi a primeira construtora brasileira a receber em 2010, as certificações das normas NBR ISO 9001, NBR ISO 1600, NBR ISO 14001, OHSAS 18001 e o PBQP-H.

O levantamento de dados foi realizado no canteiro de obras de um Edifício Residencial constituído de 01 (uma) torre com 33 (trinta e três) pavimentos, sendo 28 (vinte e oito) pavimentos tipo com 08 (oito) apartamentos cada, mezanino, térreo, subsolo 1 , subsolo 2 , subsolo 3 .

\subsection{SIMBOLOGIA ADOTADA PARA ELABORAÇÃO DO MAPEAMENTO DE FLUXO DE VALOR}


A simbologia adotada neste trabalho para elaboração do MFV é apresentada em forma de legenda juntamente com o MFV (Figuras 3, 4 e 5), a qual foi adaptada do Léxico Lean (2007).

\subsection{LEVANTAMENTO DE DADOS}

O processo de alvenaria de vedação com blocos de concreto sem função estrutural foi escolhido por ser considerado um processo crítico no planejamento da obra e com significativa importância e interferências aos subsistemas que a cercam.

O levantamento de dados ocorreu na execução do $26^{\circ}$ pavimento, observando 0 desenvolvimento de todo o processo produtivo, desde a produção de argamassa, transporte horizontal e vertical dos insumos e execução da elevação da alvenaria.

A execução do serviço de alvenaria foi acompanhada durante 02 (dois) dias de trabalho executados no decorrer da semana (terça e quartafeira), em que foram observadas, fotografadas e cronometradas as atividades desenvolvidas por 01 (um) oficial (pedreiro) e 01 (um) servente.

A área total acompanhada foi de $55,57 \mathrm{~m}^{2}$ contemplando a execução de um apartamento. Para calcular o tempo de execução desta atividade, adotou-se o tempo médio para a execução de $1,0 \mathrm{~m}^{2}$ de alvenaria.

\subsection{LEVANTAMENTO DE DADOS DO SERVIÇO DE ALVENARIA NÃO ESTRUTURAL}

Para o processo de execução de alvenaria, foram considerados os serviços de estação de trabalho, preparação do local, assentamento dos blocos e fixação do ferro cabelo, conforme descrito na Tabela 1.

Para o levantamento de dados, levou-se em consideração a definição dos seguintes parâmetros:

- Tempo total (T. Total): tempo medido de cada atividade desenvolvida em relação ao total de alvenaria executada, 55,57 $\mathrm{m}^{2}$;

- Tempo unitário (T. unit.): tempo necessário para cada atividade para a execução de $1,0 \mathrm{~m}^{2}$ de alvenaria;

- Tempo unitário mais atividades relacionadas (T. unit. ${ }^{*}$ ): tempo necessário para a execução de $1,0 \mathrm{~m}^{2}$ de alvenaria somando todas as atividades relacionadas;

- Percentual: percentual de tempo necessário a cada atividade para execução de $1,0 \mathrm{~m}^{2}$.

Foram utilizados na composição do tempo de execução das atividades no MFV atual os valores de tempo obtidos para $1,0 \mathrm{~m}^{2}$ de alvenaria executada.

\section{TABELA 1: Descrição das atividades do processo de execução de alvenaria.}

\begin{tabular}{ll}
\multicolumn{1}{c}{ Serviços } & \multicolumn{1}{c}{ Descrição das atividades } \\
\hline Estação de trabalho & $\begin{array}{l}\text { Consistem nas atividades de deslocamento da bancada de corte, bancada com } \\
\text { masseira, extensão, serra mármore e relocação de blocos (blocos próximos à } \\
\text { parede a ser executada). }\end{array}$ \\
\hline Preparação do local & $\begin{array}{l}\text { Consistem nas atividades de limpeza do local e fixação do escantilhão, verificação } \\
\text { de nível vertical, limpeza da face superior dos blocos de marcação e fixação da } \\
\text { linha. }\end{array}$ \\
\hline
\end{tabular}

Assentamento dos blocos Execução da atividade principal

Fixação ferro cabelo

Consistem na fixação do ferro cabelo para amarração dos blocos canaletas com a estrutura (pilares) onde foram executadas as contra vergas. 


\subsection{LEVANTAMENTO DE DADOS DO SERVIÇO DE CONTRAVERGAS E CINTAS DE AMARRAÇÃO}

O servente além de auxiliar a realização do serviço de alvenaria pelo pedreiro simultaneamente realiza os serviços de: limpeza, transporte manual de material, despaletização de blocos, execução de contravergas e cintas de amarração moldadas in loco.

Para a contabilização do tempo de serviço de contravergas e cintas de amarração foram relacionados os tempos cronometrados das atividades desenvolvidas para execução das contravergas e cintas de amarração.

As paredes externas recebem cintas de amarração e as paredes com abertura de janelas recebem contravergas. As paredes com abertura de janelas são executadas até a quarta fiada pelo pedreiro e após a quarta fiada executa-se uma fiada de canaleta, posteriormente o ajudante a preenche com aço e concreto.

As contravergas possuem formas metálicas para concretagem. O servente é responsável pela execução da montagem da forma, da ferragem e concretagem.

O concreto para execução destes serviços é produzido no pavimento. Para isso é disponibilizado os insumos (cimento, areia e brita) e uma betoneira de $150 \mathrm{~L}$ para produção do concreto.

A amostra de dados levantada na execução de 03 (três) contravergas totalizou 5,90 m de comprimento total, considerando a montagem da forma, corte e dobra da ferragem, mistura do concreto e concretagem.

A medição de tempo da concretagem para 03 (três) cintas de amarração de $11,32 \mathrm{~m}$ de comprimento total considerou a mistura do concreto e concretagem.

Para o levantamento de dados, levou-se em consideração a definição dos seguintes parâmetros:

- Tempo total (T. total): tempo medido de cada atividade desenvolvida em relação ao total de contravergas e cinta de amarração executadas, $5,90 \mathrm{~m}$ e $11,32 \mathrm{~m}$, respectivamente;

- Tempo unitário (T. unit.): tempo necessário a cada atividade para a execução de 1,0 m de contraverga e cinta de amarração;

- Tempo unitário mais atividades relacionadas (T. unit.*): tempo necessário para a execução de $1,0 \mathrm{~m}$ de contraverga e cinta de amarração somando todas as atividades relacionadas.

\subsection{LEVANTAMENTO RELACIONADO TRANSPORTE DE INSUMOS}

Em relação ao transporte de insumo foi destinada uma equipe, a qual foi responsável pela carga e descarga, transporte horizontal e vertical do estoque de blocos do terceiro subsolo ao pavimento.

Para o levantamento de dados, levou-se em consideração a definição dos seguintes parâmetros:

- T. médio: tempo médio para cada etapa de transporte, independente do material e equipamento utilizado;

- T. bloco: tempo necessário para o transporte dos blocos inteiros paletizados utilizando a "burrinha" hidráulica;

- T. 1/2 bloco: tempo necessário para o transporte dos meios blocos, utilizando giricas.

\subsection{CLASSIFICAÇÃO DAS ATIVIDADES DE FLUXO E ELABORAÇÃO DO MFV ATUAL E FUTURO}

Após todos os levantamentos dos serviços realizados na execução da alvenaria de blocos de concreto foi possível elaborar o MFV atual com seu respectivo tempo de execução.

Determinou-se 0 percentual das atividades de fluxo desenvolvidas durante o processamento de acordo com sua classificação, produtiva, auxiliar e improdutiva. Para isto considerou-se a classificação de Santos, Formoso e Hinks (1996).

Ao traçar o MFV atual do processo de alvenaria, foram indicados os tempos obtidos para cada serviço em relação a $1,0 \mathrm{~m}^{2}$ de alvenaria executada.

As atividades eliminadas ou reduzidas foram representadas nas intervenções ao MFV atual, após foi elaborado o MFV futuro excluindo as atividades improdutivas e expressando os tempos reduzidos. 


\subsection{ANÁLISE DO PROJETO DE MARCAÇÃO DE ALVENARIA}

O projeto de marcação de alvenaria referente ao objeto de estudo foi disponibilizado pela empresa construtora para a análise e desenvolvimento deste trabalho.

O projeto recomenda o uso de canaletas $12 \times 19 \mathrm{~cm}$ e bloco maciço de $9 \times 4 \mathrm{~cm}$ para assentamento entre os blocos completando a dimensão da fiada de marcação, no entanto, estes materiais não foram utilizados no momento da execução, sendo substituídos por cortes para adequação das medidas.

Os blocos de concreto foram produzidos no canteiro de obra, mas na produção não está incluída a produção dos materiais supracitados.

\section{ANÁLISE DE DADOS E DISCUSSÃO DE RESULTADOS}

\subsection{IDENTIFICAÇÃO DAS ATIVIDADES}

\subsubsection{Serviço de alvenaria não estrutural}

$\mathrm{Na}$ Tabela 2 está representado o tempo medido para execução de cada serviço envolvido no processo produtivo de alvenaria.

O serviço de conferência de medidas e fixação de telas atende a todas as paredes executadas, sendo somados.

Após somar todos os tempos cronometrados para os serviços descritos na Tabela 2 e reforçando que este total é relativo à execução de $55,57 \mathrm{~m}^{2}$, optou-se por gerar um tempo médio referente a $1,0 \mathrm{~m}^{2}$ de alvenaria executada, para melhor descrição no MFV atual.

O tempo médio observado para execução de alvenaria é de $10 \mathrm{~min} 49 \mathrm{seg}$ para executar 1,0 $\mathrm{m}^{2}$ de alvenaria. Ressalta-se que este tempo foi medido pelos pesquisadores e não sofreu nenhuma interferência pelo profissional responsável da empresa.

Em uma análise de percentuais é possível verificar o percentual de alguns serviços que não agregam valor ao processo, por exemplo, a realização de cortes nos blocos com um percentual equivalente a $4,68 \%$ do processo, considerando a eliminação deste serviço ter-se-ia uma redução de 30 seg em 1,0 $\mathrm{m}^{2}$ de alvenaria executada.

\subsubsection{Serviço de contravergas e cintas de amarração}

Durante a coleta de dados nesse processo, observaram-se falhas no atendimento às necessidades do pedreiro (abastecer a estação de trabalho), quando o servente executa as cintas e contravergas.

Foram medidos os tempos para execução de 03 (três) contravergas totalizando $5,90 \mathrm{~m}$ de comprimento total, para um apartamento, executadas durante um único procedimento de concretagem. Apresentando como resultado um tempo de 20 min 42 seg para execução de 1,0 m de contravergas in loco (Tabela 3 ).

Durante a medição do levantamento de dados do serviço de contravergas, foram cronometrados os tempos para a concretagem de 03 (três) cintas totalizando 11,32 m de comprimento total, para um apartamento. Para concretagem de 1,0 $\mathrm{m}$ de cinta de amarração são necessários $1 \mathrm{~min}$ 46 seg (Tabela 4). As cintas foram executadas nas paredes externas que não possuem janelas (neste caso são contravergas) e na sacada uma fiada de canaleta, cinta, para fixação do guarda corpo.

\subsection{PRODUÇÃO E TRANSPORTE DE ARGAMASSA}

A argamassa de assentamento é produzida no canteiro, a central de argamassa fica localizada no subsolo da obra.

O transporte é realizado por giricas, abastecendo inicialmente a masseira do pavimento, para posterior abastecimento da masseira de uso pessoal do profissional. Para o transporte vertical de material são utilizados 02 (dois) elevadores, um tipo cremalheira e um a cabo. O tempo médio do transporte de material por viagem até o $26^{\circ}$ pavimento é de aproximadamente 11 minutos, contados deste o transporte horizontal no subsolo e pavimento mais o tempo de subida e descida do elevador. 
TABELA 2: Resultados do levantamento de dados do serviço de alvenaria não estrutural.

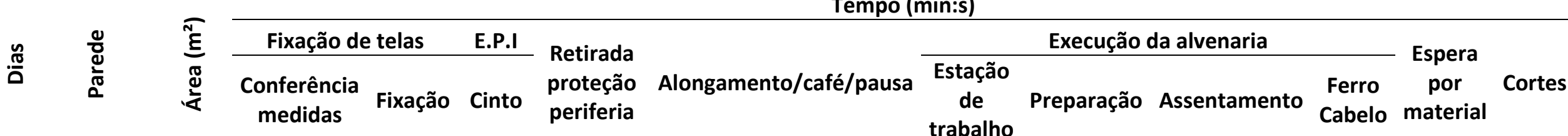

\begin{tabular}{|c|c|c|c|c|c|c|c|c|c|c|c|c|c|}
\hline \multirow{9}{*}{$\stackrel{\circ}{\rightarrow}$} & 1 - meia & 4,82 & \multirow{16}{*}{$18: 28$} & \multirow{8}{*}{$13: 17$} & 04:59 & 02:33 & 08:10 & - & 09:51 & 25:09 & - & - & - \\
\hline & 2 - meia & 2,51 & & & - & 03:00 & - & 01:10 & $04: 36$ & $16: 11$ & - & $04: 40$ & - \\
\hline & 3 & 10,00 & & & - & - & 06:20 & 03:03 & $07: 52$ & $45: 00$ & - & - & $00: 43$ \\
\hline & 4 - meia & 2,58 & & & - & - & - & - & $06: 52$ & $10: 10$ & - & - & - \\
\hline & 5 & 4,20 & & & - & - & - & - & 05:50 & $40: 52$ & - & 03:32 & - \\
\hline & 6 & 2,57 & & & 02:10 & - & - & 07:56 & 04:04 & $12: 34$ & 03:21 & - & $02: 57$ \\
\hline & 7 & 2,03 & & & - & - & - & - & $06: 42$ & $11: 38$ & 01:50 & - & 01:00 \\
\hline & 8 - 1 fiada & 0,90 & & & - & - & - & - & - & 09:00 & 01:17 & - & - \\
\hline & 9 & 4,56 & & \multirow{2}{*}{$01: 30$} & - & - & 04:17 & - & $04: 50$ & $26: 01$ & - & - & - \\
\hline \multirow{7}{*}{$\stackrel{\circ}{\sim}$} & 11 & 3,20 & & & - & - & - & $05: 37$ & 01:30 & $23: 50$ & - & - & 03:01 \\
\hline & 12 & 1,92 & & \multirow{6}{*}{$04: 23$} & - & - & - & - & 05:14 & $16: 11$ & $00: 55$ & $00: 54$ & $03: 12$ \\
\hline & 13 & 1,44 & & & - & - & $00: 50$ & - & 09:50 & $08: 45$ & 01:54 & - & $00: 38$ \\
\hline & 14 & 0,58 & & & - & - & - & - & $03: 49$ & $04: 35$ & - & $07: 57$ & $02: 36$ \\
\hline & 15 & 8,86 & & & - & - & - & $02: 41$ & $17: 01$ & $56: 20$ & - & $02: 39$ & $08: 56$ \\
\hline & 16 & 4,16 & & & - & - & 03:01 & 03:36 & 06:05 & $32: 08$ & - & - & 05:06 \\
\hline & 17 & 1,24 & & & - & - & 01:47 & - & $02: 49$ & $10: 14$ & - & - & - \\
\hline \multicolumn{2}{|c|}{1 - T. total } & 55,57 & \multicolumn{2}{|l|}{$37: 38$} & 07:09 & 05:33 & $24: 25$ & 24:03 & $36: 55$ & $48: 38$ & 09:17 & 19:42 & 28:09 \\
\hline \multicolumn{2}{|c|}{2 - T. unit. } & 1,00 & \multicolumn{2}{|l|}{$00: 41$} & 00:08 & 00:06 & $00: 26$ & $00: 26$ & $01: 45$ & $06: 16$ & 00:10 & $00: 21$ & $00: 30$ \\
\hline \multicolumn{2}{|c|}{3 - T. unit.* } & 1,00 & \multicolumn{11}{|c|}{$10: 49$} \\
\hline \multicolumn{2}{|c|}{4 - Percentual } & 1,00 & \multicolumn{2}{|l|}{$6,26 \%$} & $1,19 \%$ & $0,92 \%$ & $4,06 \%$ & $4,00 \%$ & $16,11 \%$ & $57,96 \%$ & $1,54 \%$ & $3,28 \%$ & $4,68 \%$ \\
\hline
\end{tabular}


TABELA 3: Resultados do levantamento de dados do serviço de contravergas.

\begin{tabular}{cccccc}
\multirow{2}{*}{ Parede } & Comprimento $(\mathrm{m})$ & \multicolumn{4}{c}{ Tempo (mm:ss) } \\
\cline { 3 - 4 } & & Forma & Ferragem & Concreto & Concretagem \\
\hline Cozinha & 3,10 & $12: 47$ & $12: 47$ & & $05: 58$ \\
\cline { 1 - 4 } Quarto & 1,20 & $05: 05$ & $02: 58$ & $00: 10$ & $04: 28$ \\
\hline Suíte & 1,60 & $09: 01$ & $04: 01$ & & $04: 56$ \\
\hline 1) Total & 5,90 & $26: 53$ & $19: 46$ & $00: 10$ & $15: 22$ \\
\hline 2) Total & 1,00 & $04: 33$ & $13: 31$ & $00: 02$ & $02: 36$ \\
\hline 3) Total & 1,00 & & & $20: 42$ & \\
\hline
\end{tabular}

FONTE: Autoria Própria.

TABELA 4: Resultado do levantamento de dados do serviço de cintas de armação.

\begin{tabular}{cccc}
\multirow{2}{*}{ Parede } & Comprimento $(\mathrm{m})$ & & Tempo (mm:ss) \\
& & Concreto & Concretagem \\
\hline Bh Suíte & 2,52 & & $05: 31$ \\
\hline Sacada & 3,98 & $00: 11$ & $06: 33$ \\
\cline { 1 - 1 } Suíte & 4,82 & & $07: 39$ \\
\hline 1) Total & 11,32 & $00: 11$ & $19: 43$ \\
\hline 2) Total & 1,00 & $00: 01$ & $01: 45$ \\
\hline 3) Total & 1,00 & & $01: 46$ \\
\hline
\end{tabular}

\subsection{PRODUÇÃO E TRANSPORTE DOS BLOCOS E CANALETAS DE CONCRETO}

Os blocos e canaletas de concreto para vedação são produzidos no canteiro da obra, em sua composição é utilizado o resíduo classe $A$. Estes resíduos são reciclados em obra, em seguida são utilizados como agregado inerte na fabricação dos blocos de concreto para vedação (Quadro 1).

Esses blocos e canaletas são produzidos e paletizados pela equipe da empresa. O primeiro armazenamento ocorre no subsolo, e conforme a liberação das frentes do serviço de alvenaria nos pavimentos é realizado o transporte até o pavimento.

Os blocos de concreto para vedação e canaletas são produzidos em obra nas dimensões ilustradas na Figura 1.

O transporte é realizado de forma aleatória, sem nenhum registro físico da quantidade e tipo de blocos já deixados no pavimento e sem orientação quanto à disposição no pavimento.

Os blocos e canaletas de $9 \times 19 \times 39 \mathrm{~cm}$ e $12 \times 19 \times 39 \mathrm{~cm}$ são paletizados, facilitando seu transporte horizontal com a utilização da "burrinha hidráulica". Os meios blocos de $9 \times 19 \times 19 \mathrm{~cm}$ e $12 \times 19 \times 19 \mathrm{~cm}$ não são paletizados, por não oferecerem estabilidade sobre os paletes durante $o$ transporte.

Seu transporte é realizado por giricas e a carga realizada no momento deste transporte. A quantidade utilizada por pavimento é significativamente inferior em relação aos blocos inteiros e canaletas, no entanto é possível otimizar o estoque e transporte.

A Tabela 5 apresenta a medição do transporte de blocos e a diferença entre o transporte com paletes e com giricas.

O transporte racionalizado com uso de paletes e "burrinha hidráulica" possibilita um ganho 
de tempo ao transporte de $02 \mathrm{~min} 41 \mathrm{seg}$ em comparação ao transporte por giricas, no qual ocorre a carga no momento do transporte.

Analisando apenas o transporte horizontal por paletes observou-se uma diferença média de $01 \mathrm{~min} 12$ seg entre o transporte horizontal realizado no pavimento e no subsolo. No subsolo os blocos estão paletizados em local especifico. No pavimento tipo não possui uma definição prévia para disposição dos paletes.

Considerando o tempo total de transporte por paletes e subtraindo pela diferença do transporte horizontal no subsolo versus pavimento, pode-se reduzir o tempo de transporte para $9 \mathrm{~min}$ 46 seg.

\section{QUADRO 1: Resíduos Classe A gerados na obra e destinação.}

\begin{tabular}{|l|c|c|c|l|}
\hline Resíduos gerados na obra & Reciclado na obra & Descartado & Tratamento & Aplicação \\
\hline Bloco de concreto & $\mathrm{x}$ & & Triturado & \multirow{2}{*}{$\begin{array}{l}\text { Fabricação de blocos de concreto e } \\
\text { Argamassas }\end{array}$} \\
\hline Concreto & $\mathrm{x}$ & $\mathrm{x}$ & Caçamba & Descarte \\
\hline Material cerâmico & & $\mathrm{x}$ & - & Descarte \\
\hline Solos & & $\mathrm{x}$ & Caçamba & Reciclagem \\
\hline Gesso & & & & \\
\hline
\end{tabular}

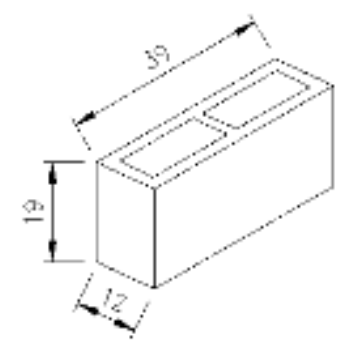

a) $12 \times 39 \times 19 \mathrm{~cm}$

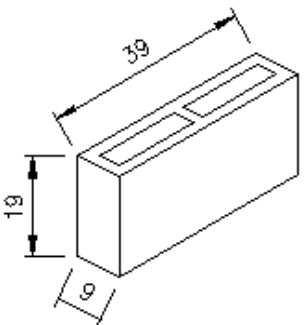

b) $9 \times 39 \times 19 \mathrm{~cm}$

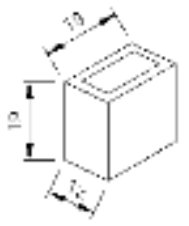

c) $12 \times 19 \times 19 \mathrm{~cm}$
FONTE: Autoria Própria.

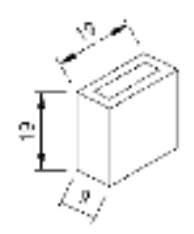

d) $9 \times 19 \times 19 \mathrm{~cm}$

FIGURA 1: Blocos produzidos pela empresa.

FONTE: Autoria Própria.

TABELA 5: Medição de tempo para o transporte de blocos de concreto.

\begin{tabular}{|c|c|c|c|c|c|c|c|}
\hline \multirow{3}{*}{ Medição } & \multicolumn{5}{|c|}{ Tempo (mm:ss) } & \multirow{3}{*}{ Material } & \multirow{3}{*}{ Percurso } \\
\hline & \multicolumn{2}{|c|}{ Horizontal } & \multicolumn{2}{|c|}{ Vertical } & \multirow{2}{*}{ Total } & & \\
\hline & Subsolo & Pavt $^{\circ}$ & Subida & Descida & & & \\
\hline 1 & 01:56 & $03: 52$ & 02:52 & 02:35 & $11: 15$ & Bloco - palete & Uma parada \\
\hline 2 & 01:56 & $03: 17$ & $02: 38$ & $02: 22$ & $10: 13$ & Bloco - palete & Sem parada \\
\hline 3 & $02: 49$ & 03:03 & 03:13 & $02: 36$ & $11: 41$ & Canaleta - palete & Uma parada \\
\hline 4 & $04: 50$ & $03: 26$ & 03:01 & $02: 22$ & $13: 39$ & Meio bloco - girica & Uma parada \\
\hline 5 & $02: 12$ & $03: 29$ & $02: 40$ & $02: 24$ & $10: 45$ & Bloco - palete & Sem parada \\
\hline T. Médio & $02: 21$ & $02: 39$ & $02: 18$ & $01: 57$ & 09:16 & Média elaborada & medições \\
\hline T. Bloco & $02: 24$ & $02: 27$ & 02:13 & 01:50 & $08: 53$ & Transporte & etes \\
\hline T. $1 / 2$ bloco & $02: 12$ & $03: 29$ & 02:40 & $02: 24$ & $10: 45$ & Transporte & icas \\
\hline
\end{tabular}


5.4 ANÁlISE DO PROJETO DE MARCAÇÃO DE ALVENARIA

Destaca-se a falta de compatibilidade entre o projeto e a execução, reforçando a necessidade de adequação do projeto com a fabricação dos blocos que é realizada no canteiro da obra. No projeto indica o uso de canaletas de $12 \times 19 \mathrm{~cm}$ e bloco maciço de $9 \times 4 \mathrm{~cm}$, no entanto, estes materiais não foram utilizados no momento da execução, sendo substituídos por cortes para adequação das medidas.

\subsection{EXECUÇÃO DA ALVENARIA}

Para a coleta de dados no primeiro dia verificou se as atividades predecessoras no $26^{\circ}$ pavimento estavam concluídas.

$\mathrm{Na}$ Figura 2 estão relacionadas as atividades realizadas durante 0 processo produtivo.

Acompanhou-se o trabalho realizado por 01 (um) pedreiro para execução do pavimento, o qual obedece a uma sequência de serviços de forma habitual, o que poderá ser observado no MFV Atual.

\subsection{CLASSIFICAÇÃO DAS ATIVIDADES DE FLUXO}

As atividades de fluxo levantadas no processo produtivo de alvenaria deste trabalho foram classificadas em produtivas, auxiliares e improdutivas, sejam elas desenvolvidas pelo oficial, servente ou transporte (Quadro 2).

A classificação utilizada foi definida no item 2.1 por Santos, Formoso e Hinks (1996) e aplicada na elaboração do MFV atual.

No Quadro 2 por meio da elaboração do
MFV atual (Figura 3), o fluxo de atividades realizadas se tornou transparente antes e durante $o$ processo produtivo de alvenaria.

Está representando o resumo em percentual de tempo para a classificação das atividades desenvolvidas pelo oficial durante o processamento. Estas atividades foram utilizadas para a elaboração do MFV Atual.

\subsection{MFV}

A partir da análise MFV do estado atual foi possível à proposição de melhorias, a fim de reduzir a parcela das atividades improdutivas, otimizar as atividades auxiliares e aumentar a parcela das atividades produtivas. Com as mudanças propostas foi elaborado o MFV do estado futuro.

\subsubsection{MFV atual}

Por meio da elaboração do MFV atual (Figura 3) o fluxo de atividades realizadas antes e durante $\mathrm{o}$ processo produtivo de alvenaria se tornou transparente. Por meio deste foi possível avaliar o tempo de execução dos serviços envolvidos no processo, sendo: $10 \mathrm{~min} 49 \mathrm{seg}$ por $1,0 \mathrm{~m}^{2}$ de alvenaria executada; $11 \mathrm{~min} 31 \mathrm{seg}$ de transporte; $20 \mathrm{~min} 42 \mathrm{seg}$ por 1,0 m de contraverga executada; $1 \mathrm{~min} 46 \mathrm{seg}$ por 1,0 m de cinta de amarração executada.

$\mathrm{Na}$ Figura 4 estão representadas as atividades que sofreram intervenção, sejam elas por exclusão ou adequação ao fluxo de serviço. 


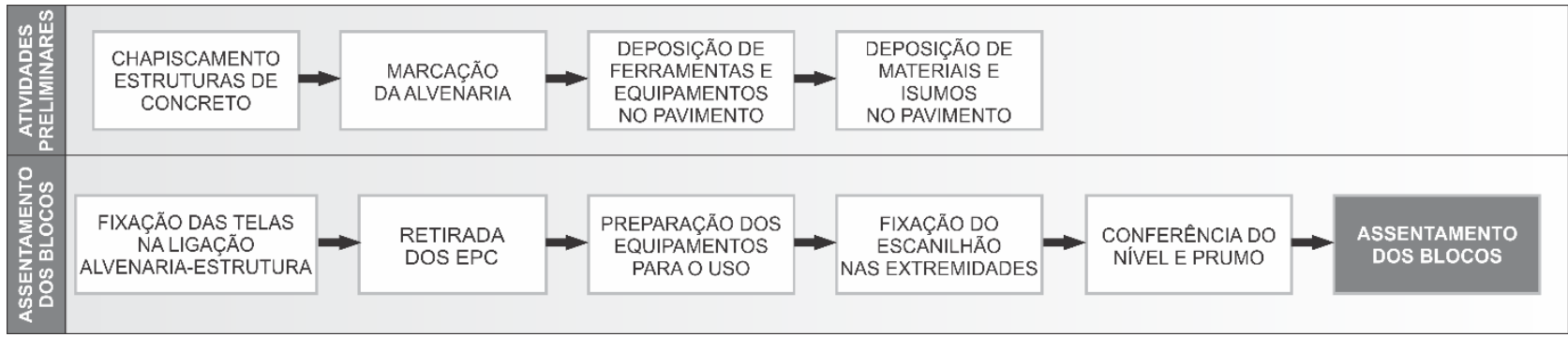

FIGURA 2: Atividades predecessoras do 26 pavimento.

FONTE: Autoria Própria.

\begin{tabular}{|c|c|c|c|}
\hline Classificação & Atividades & Percentual & Total \\
\hline \multirow{3}{*}{ Produtivas } & Fixação de telas & $6,26 \%$ & \multirow{3}{*}{$65,76 \%$} \\
\hline & Fixação de ferro cabelo & $1,54 \%$ & \\
\hline & Assentamento & $57,96 \%$ & \\
\hline \multirow{3}{*}{ Auxiliares } & Preparação do local & $16,11 \%$ & \multirow{3}{*}{$21,30 \%$} \\
\hline & E.P.I. & $1,19 \%$ & \\
\hline & Estação de trabalho & $4,00 \%$ & \\
\hline \multirow{4}{*}{ Improdutivas } & Retirada de proteções & $0,92 \%$ & \multirow{4}{*}{$12,94 \%$} \\
\hline & Alongamento/café/pausa & $4,06 \%$ & \\
\hline & Espera por material & $3,28 \%$ & \\
\hline & Realização de cortes & $4,68 \%$ & \\
\hline
\end{tabular}

FONTE: Autoria Própria.

\subsubsection{MFV futuro}

Foram propostas mudanças a serem realizadas no processo executivo e ilustradas no MFV do estado futuro. No entanto, elas não foram aplicadas e os tempos calculados são estimativas a partir dos levantamentos realizados pelo MFV do estado atual.

No MVF futuro proposto se observa um novo fluxo e redução no tempo para a execução do processo produtivo (Figura 5). 0 tempo passou a ser de $08 \mathrm{~min} 44$ seg para a execução de $1,00 \mathrm{~m}^{2}$ de alvenaria, com uma redução de 2 min 05 seg. Podese perceber no MFV futuro uma redução das atividades para o processo construtivo de alvenaria: - O tempo medido na estação de trabalho é a união dos tempos gastos na movimentação de bancadas para corte e masseira, serra mármore e extensão. A eliminação de cortes de blocos eliminaria o uso de bancada para corte, serra mármore e extensão. Ficando apenas a movimentação da bancada de corte, apresentando a redução de $75 \%$ do tempo desta atividade.

- Transformação das atividades de fluxo em atividades predecessoras: fixação de telas, execução de vergas e contravergas;

- Projeto de alvenaria racionalizado: eliminação de cortes;

- Supermercado: blocos racionalizados, vergas e contravergas pré-moldadas, concreto pronto para cintas.

- Utilização de kanban de sinalização, retirada e produção. 


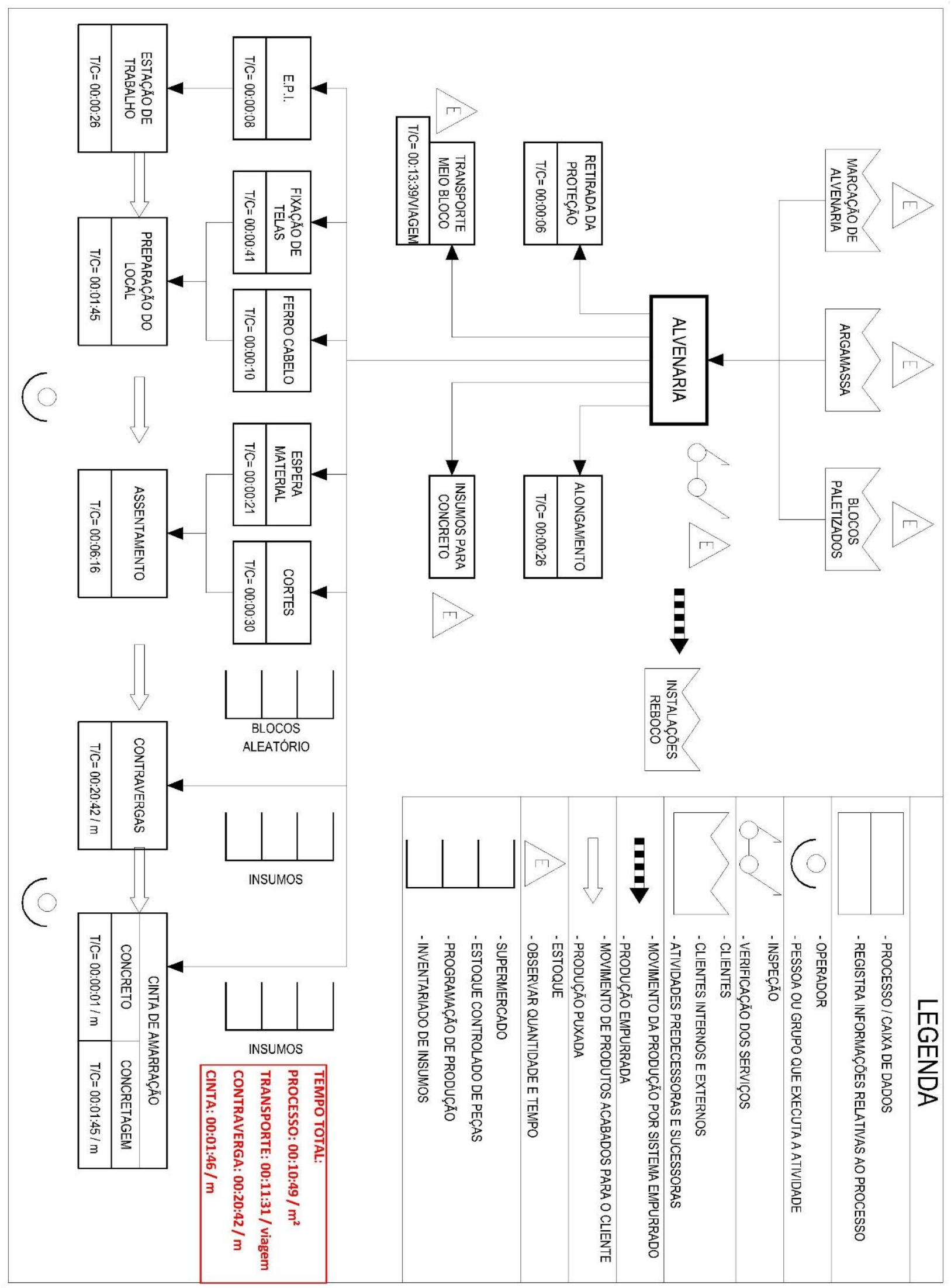

FIGURA 3: MFV Atual.

FONTE: Autoria Própria. 


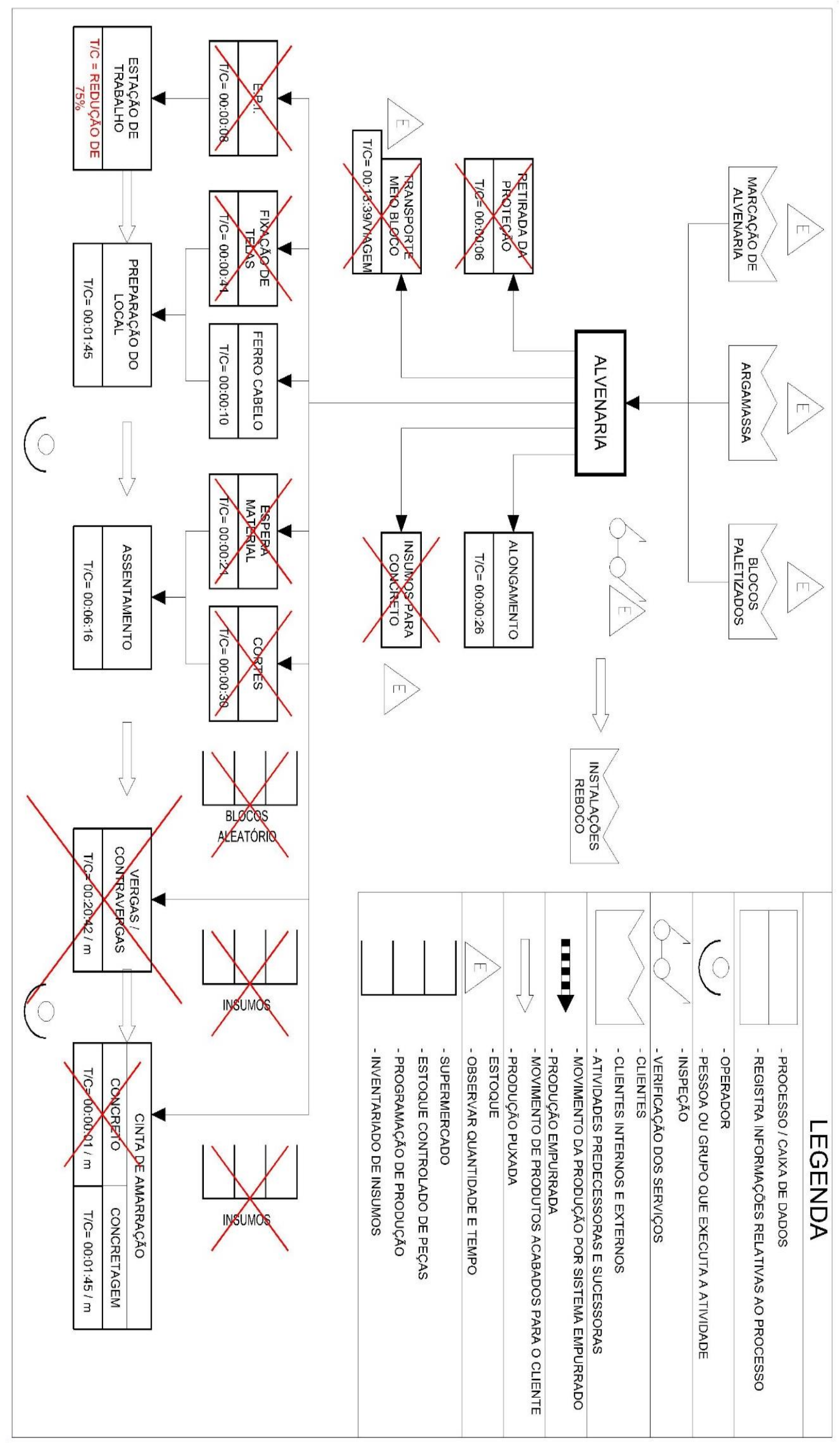

FIGURA 4 : Intervenções no MFV Atual.

FONTE: Autoria Própria. 
No Quadro 3 está apresentado o resumo das atividades que foram eliminadas ou reduzidas na elaboração do MFV futuro, possibilitando comparar os percentuais das atividades desenvolvidas atualmente com as atividades a serem implementadas.

Algumas atividades listadas como improdutivas não foram computadas nesta medição por serem executadas pelo servente ou pela equipe do transporte. O Quadro 3 lista apenas as atividades executadas pelo oficial.

Comparando os tempos de execução das atividades realizadas pelo oficial no MFV atual com o MFV futuro, pode-se pressupor que o novo fluxo apresente as seguintes melhorias: redução de 2 minutos e 5 segundos, ou seja, redução de 19,32\% no tempo de execução da alvenaria. Redução de 41 segundos nas atividades produtivas, 0 que representa redução de 6,32\% do tempo de execução da alvenaria. Redução 27 segundos nas atividades auxiliares, o que representa redução de 4,16\% do tempo de execução da alvenaria. Redução de 58 segundos nas atividades improdutivas, o que representa redução de $8,93 \%$ do tempo de execução da alvenaria. Redução de 1 minuto e 45 segundos nas atividades de transporte, resultando em redução de $15,19 \%$ no tempo total de transporte. Eliminação da execução de contravergas e vergas no pavimento. Apenas concretagem das cintas, eliminando concreto no pavimento.

\begin{tabular}{|c|c|c|c|}
\hline Classificação & Atividades & Percentual & Total \\
\hline \multirow{3}{*}{ Produtivas } & Fixação de telas & $0,00 \%$ & \multirow{3}{*}{$73,76 \%$} \\
\hline & Fixação de ferro cabelo & $1,91 \%$ & \\
\hline & Assentamento & $71,84 \%$ & \\
\hline \multirow{3}{*}{ Auxiliares } & Preparação do local & $19,97 \%$ & \multirow{3}{*}{$21,21 \%$} \\
\hline & E.P.I. & $0,00 \%$ & \\
\hline & Estação de trabalho & $1,24 \%$ & \\
\hline \multirow{4}{*}{ Improdutivas } & Retirada de proteções & $0,00 \%$ & \multirow{4}{*}{$5,03 \%$} \\
\hline & Alongamento/café/pausa & $5,03 \%$ & \\
\hline & Espera por material & $0,00 \%$ & \\
\hline & Realização de cortes & $0,00 \%$ & \\
\hline
\end{tabular}




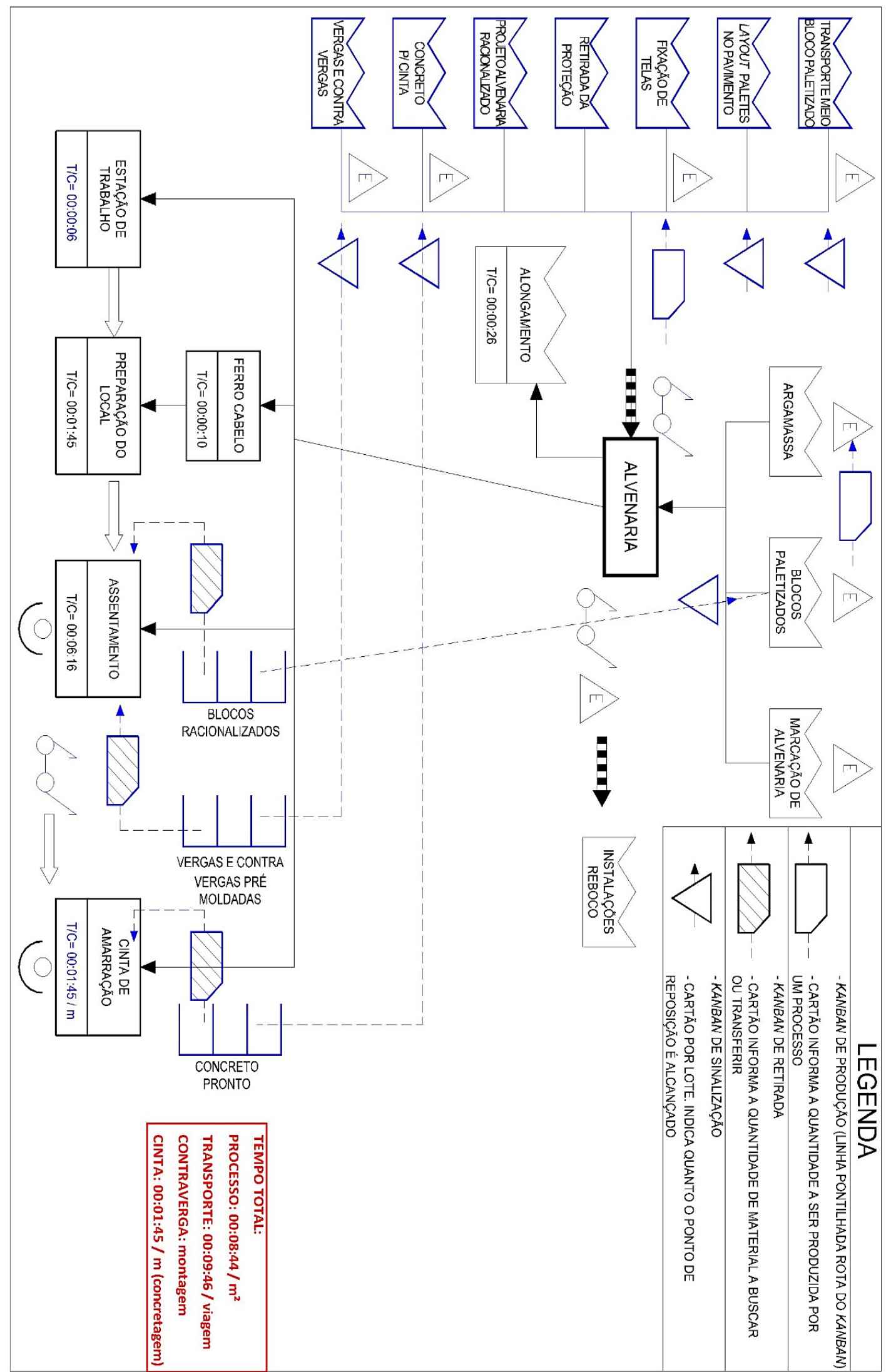

FIGURA 5: MFV Futuro.

FONTE: Autoria Própria. 


\subsection{DIRETRIZES LEAN PARA IMPLANTAÇÃO DA MELHORIA CONTINUA}

No Quadro 4 são apresentadas as diretrizes utilizando as ferramentas Lean, as quais foram apresentadas ao engenheiro responsável pela empresa para validação e como sugestão para implantação futura buscando a melhoria contínua.

\section{QUADRO 4: Diretrizes lean.}

\begin{tabular}{|c|c|c|c|c|}
\hline Atividade atual & Situação atual & Diretrizes & Objetivo & Como aplicar \\
\hline $\begin{array}{l}\text { Transporte } \\
\text { meio bloco }\end{array}$ & $\begin{array}{l}\text { Transporte realizado por } \\
\text { giricas; } \\
\text { Carregamento no } \\
\text { momento do transporte }\end{array}$ & $\begin{array}{l}\text { Paletizar os meio } \\
\text { blocos }\end{array}$ & $\begin{array}{ll}\text { Racionalizar } & \mathrm{o} \\
\text { transporte } & \mathrm{e} \\
\text { estocagem } & \end{array}$ & $\begin{array}{l}\text { Paletizar meio bloco e } \\
\text { amarrar com fita; } \\
\text { Adquirir transpalete }\end{array}$ \\
\hline $\begin{array}{l}\text { Transporte } \\
\text { manual de } \\
\text { material; } \\
\text { Espera por } \\
\text { material; } \\
\text { Despaletização } \\
\text { aleatória }\end{array}$ & $\begin{array}{l}\text { Material é disposto de } \\
\text { forma aleatória }\end{array}$ & $\begin{array}{l}\text { Elaborar projeto } \\
\text { de Layout dos } \\
\text { paletes no } \\
\text { pavimento }\end{array}$ & $\begin{array}{l}\text { Informar o tipo, } \\
\text { local e quantidade } \\
\text { de blocos por } \\
\text { pavimento }\end{array}$ & $\begin{array}{l}\text { Elaborar projeto específico, } \\
\text { treinar e informar a equipe } \\
\text { de transporte. } \\
\text { Disponibilizar o layout no } \\
\text { pavimento }\end{array}$ \\
\hline $\begin{array}{l}\text { Descarga } \\
\text { blocos } \\
\text { pavimento }\end{array}$ & $\begin{array}{l}\text { Não há controle de } \\
\text { estoque de blocos }\end{array}$ & $\begin{array}{ll}\text { Criar } & \\
\text { inventariado } & \text { de } \\
\text { blocos } & \text { no } \\
\text { pavimento } & \end{array}$ & $\begin{array}{l}\text { Controle de } \\
\text { estoque }\end{array}$ & $\begin{array}{l}\text { Utilizar cartões Kanbans de } \\
\text { entrada e saída de material }\end{array}$ \\
\hline Fixação de telas & $\begin{array}{l}\text { Telas fixadas nos pilares } \\
\text { para inicio do serviço de } \\
\text { alvenaria }\end{array}$ & $\begin{array}{l}\text { Criar serviço de } \\
\text { fixação de telas }\end{array}$ & $\begin{array}{lr}\text { Eliminar } & \text { uma } \\
\text { atividade dentro } \\
\text { do processo } \\
\text { produtivo } \\
\text { alvenaria de }\end{array}$ & $\begin{array}{l}\text { Utilizar a equipe de } \\
\text { marcação de alvenaria }\end{array}$ \\
\hline $\begin{array}{l}\text { Realização de } \\
\text { cortes dos blocos }\end{array}$ & $\begin{array}{l}\text { Oficial realiza diversas } \\
\text { paradas para realização } \\
\text { de cortes de blocos }\end{array}$ & $\begin{array}{l}\text { Elaborar projeto } \\
\text { de alvenaria } \\
\text { racionalizada }\end{array}$ & $\begin{array}{l}\text { Reduzir a perda de } \\
\text { tempo } \quad \text { por } \\
\text { realização } \\
\text { cortes }\end{array}$ & $\begin{array}{l}\text { Elaborar projeto } \\
\text { compatível com a fábrica } \\
\text { ou adequar a fábrica ao } \\
\text { projeto }\end{array}$ \\
\hline $\begin{array}{l}\text { Execução de } \\
\text { contra vergas e } \\
\text { vergas }\end{array}$ & $\begin{array}{l}\text { Contra vergas e vergas } \\
\text { são moldadas in loco pelo } \\
\text { servente }\end{array}$ & $\begin{array}{l}\text { Produzir vergas e } \\
\text { contra vergas } \\
\text { previamente no } \\
\text { canteiro }\end{array}$ & \begin{tabular}{l}
\multicolumn{3}{l}{ Reduzir a perda de } \\
tempo por \\
confecção de \\
vergas e contra \\
vergas durante o \\
processo
\end{tabular} & $\begin{array}{l}\text { Criar equipe responsável } \\
\text { pela confecção de pré- } \\
\text { moldados no canteiro }\end{array}$ \\
\hline $\begin{array}{ll}\text { Concretagem } & \text { de } \\
\text { cinta } & \text { de } \\
\text { amarração } & \end{array}$ & $\begin{array}{l}\text { O concreto utilizado nas } \\
\text { cintas é produzido no } \\
\text { pavimento }\end{array}$ & $\begin{array}{l}\text { Produzir } \\
\text { concreto } \\
\text { central } \\
\text { concreto }\end{array}$ & $\begin{array}{l}\text { Fornecer pronto } \\
\text { concreto pro } \\
\text { no pavimento }\end{array}$ & $\begin{array}{l}\text { Programar a concretagem } \\
\text { das cintas em acordo com a } \\
\text { central de concreto }\end{array}$ \\
\hline
\end{tabular}




\section{CONCLUSÕES}

O levantamento realizado é uma amostragem em relação à quantidade total do serviço de alvenaria do edifício estudado, os percentuais informados são apenas para referenciar as eliminações e/ou reduções ao se propor às melhorias ao processo estudado.

A elaboração do MFV atual tornou visível o fluxo de produção de alvenaria de vedação, identificando e classificando as atividades, as fontes de desperdício, os gargalos na produção, as falhas de comunicação e informação aos envolvidos diretamente no processo, identificando também gargalos no planejamento, projetos executivos e fabricação dos blocos de concreto.

Buscando a melhoria do processo estudado foi traçado o MFV futuro e as diretrizes a partir das atividades identificadas e classificadas como produtivas, improdutivas e auxiliares. Tendo esta como referencial, pode-se direcionar o MFV futuro e as diretrizes de forma pontual, descrevendo a situação atual e propondo a implementação de ferramentas e/ou gerenciamento para a empresa.

Para obter os resultados planejados no MFV futuro é necessário o comprometimento gerencial da empresa, transmissão e transparência das ferramentas a serem implantadas.

Mesmo que a empresa estudada não faça uso de conceitos e ferramentas Lean no gerenciamento, ela utiliza equipamentos, transporte e insumos de forma racionalizada o que facilitaria a implantação das diretrizes propostas ao processo, sem custos iniciais, apenas melhorando as práticas utilizadas e proporcionando continuidade ao fluxo dos processos produtivos da empresa.

A implementação das diretrizes propostas no processo produtivo de alvenaria desta empresa juntamente com as ferramentas Lean poderia proporcionar reduções no tempo de ciclo e tornar o processo transparente aos envolvidos.

\section{REFERÊNCIAS BIBLIOGRÁFICAS}

BØLVIKEN, T.; ROOKE, J.; KOSKELA, L. The Wastes of Production in Construction - a TFV Based Taxonomy. In:
22ND ANNUAL CONFERENCE OF THE INTERNATIONAL GROUP FOR LEAN CONSTRUCTION. 2014. Disponível em: <http://www.iglc.net/Papers/Details/1076>. Acesso em: 22 mar. 2016

BRANDSTETTER, M. C. G. DE O.; SANTOS, F. C. DOS; CARASEK, $\mathrm{H}$. Avaliação das melhorias obtidas por meio da implantação do projeto de alvenaria de vedação. Ambiente Construído, v. 13, n. 3, p. 79-98, 17 set. 2013.

BULHÕES, I. R.; PICCHI, F. A. Diretrizes para a implementação de fluxo contínuo em obras de edificações. Ambiente Construído, v. 11, n. 4, p. 205-223, 29 dez. 2011.

ISHIWATA, J. IE for the Shop Floor: productivity through process analysis. Portland: Productivity Press, 1991.

MARCHWINSKI, C.; SHOOK, J. Léxico Lean: glossário ilustrado para praticantes do Pensamento Lean. São Paulo: Lean Institute Brasil, 2003.

OHNO, Taiichi. O Sistema Toyota de Produção: além da produção em larga escala. Porto Alegre: Bookman, 1997.

KOSKELA, L. Application of the new production philosophy to construction. Center for Integrated Facility Engineering. 1992. 87f. Technical Report. Finland VTT Building Technology, Finland, 1992.

KOSKELA, L.; SACKS, R.; ROOKE, J. A Brief History of the Concept of Waste in Production. In: 20TH ANNUAL CONFERENCE OF THE INTERNATIONAL GROUP FOR LEAN CONSTRUCTION. 2012. Disponível em: <http://www.iglc.net/Papers/Details/794>. Acesso em: 22 mar. 2016.

KOSKELA, L.; B $\varnothing L$ LIKEN, T. Which Are the Wastes of Construction? . In: 21TH ANNUAL CONFERENCE OF THE INTERNATIONAL GROUP FOR LEAN CONSTRUCTION. 2013. Disponível em: <http://www.iglc.net/Papers/Details/919>. Acesso em: 21 mar. 2016.

PASQUALINI, F.; ZAWISLAK, P. A. Value Stream Mapping in Construction: A Case Study in a Brazilian Construction Company. . In: 13TH ANNUAL CONFERENCE OF THE INTERNATIONAL GROUP FOR LEAN CONSTRUCTION. $2005 . \quad$ Disponível em: <http://www.iglc.net/Papers/Details/356>. Acesso em: 25 mar. 2016

PÉREZ, C. T.; COSTA, D. B.; GONÇALVES, J. P. Identificação, mensuração e caracterização das perdas por transporte em processos construtivos. Ambiente Construído, v. 16, n. 1, p. 243-263, 18 set. 2015.

SANTOS, A.; FORMOSO, C. T.; HINKS, J. Method of Intervention on the Flow of Materials in Buildings Processes. In: ANNUAL CONFEENCE OF THE INTERNATIONAL GROUP FOR LEAN CONSTRUCTION, 4., Birmingham, 1996. Proceedings... Birmingham, 1996. 
SOMMER, L. Contribuições para um método de identificação de perdas por improvisação em canteiros de obras. Porto Alegre, 2010. Dissertação (Mestrado em Engenharia Civil) - Núcleo Orientado Para Inovação da Edificação, Programa de Pós-Graduação em engenharia civil, Universidade Federal do Rio Grande do sul, Porto Alegre, 2010.

WERKEMA, Cristina. Lean Seis sigma: Introdução às ferramentas do Lean Manufacturing. 2. ed.: Elsevier, 2012. 120 p. 